\title{
El phylum Microsporidia
}

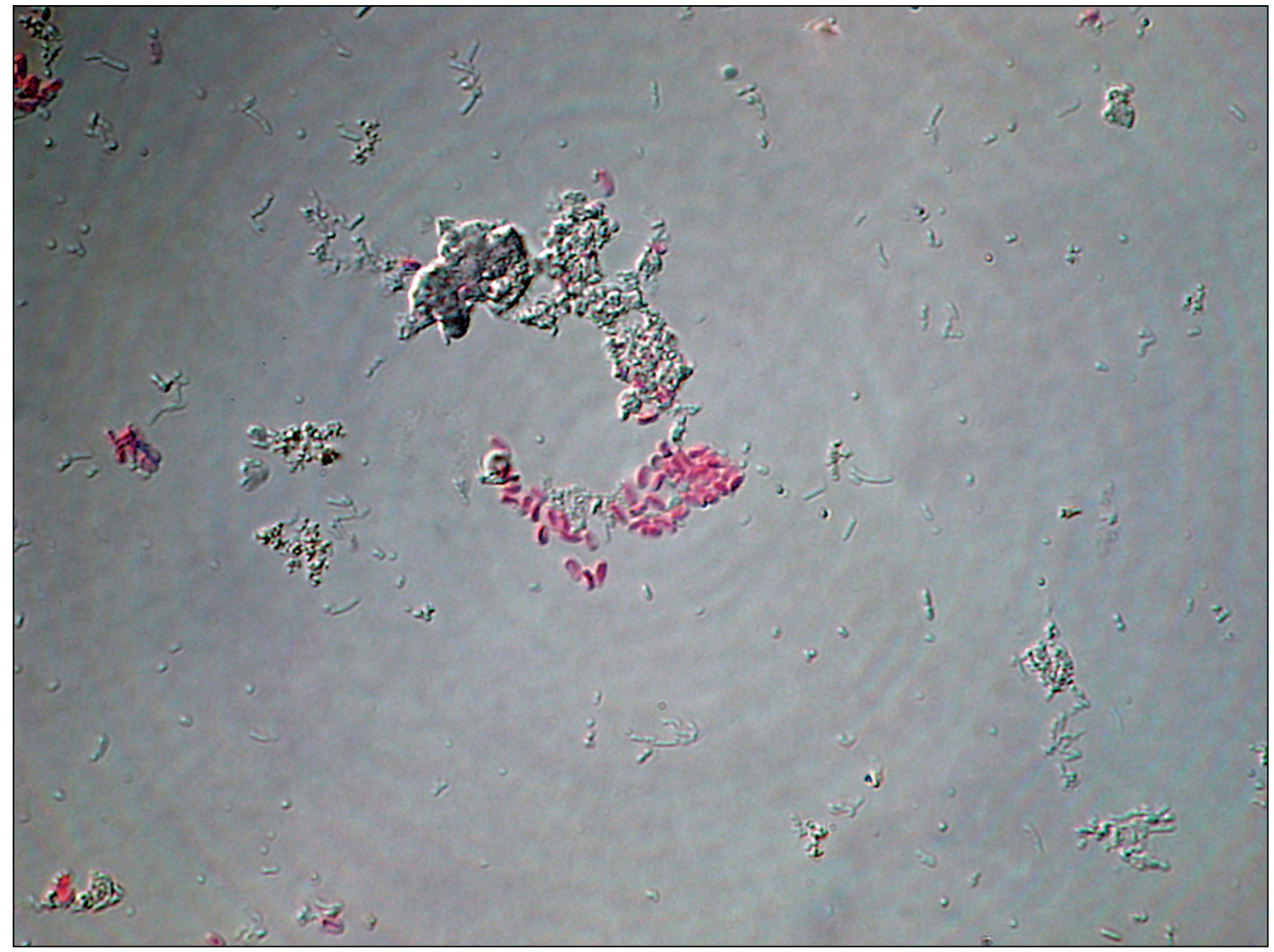

Figura 1. Microsporidios teñidos con Chromotrope 2R. 


\section{El phylum Microsporidia}

El phylum Microsporidia es un grupo de organismos eucariontes, unicelulares y ubicuos, que desarrollan parasitismo intracelular estricto. Fue descrito a mediados del siglo XIX con la identificación de Nosema bombycis como el organismo responsable de la pebrina en los gusanos de la seda. Inicialmente fue clasificado como un "hongo similar a levaduras", después como protozoo y luego como un linaje de "eucariontes primitivos". Esto último basado en estudios con microscopia electrónica que mostraba ausencia de características eucariotas, como aparato de Golgi, peroxisomas, mitocondrias y microtúbulos 9+2. Posteriormente, en la década de 1990, variados análisis de filogenia molecular, con estudios de genes y regiones de rADN evidenciaron la relación de Microsporidia con el reino de los hongos, ya fuese como una rama basal o como un grupo hermano. Además, existe evidencia biológica que apoya esta relación, pues Microsporidia posee quitina en la pared de sus esporas y almacena trehalosa, la que es probablemente su mayor reserva de azúcares, tal como ocurre con muchas especies fúngicas. A la fecha, se han descrito aproximadamente 1.400 especies pertenecientes a 200 géneros que infectan como parásitos a un gran número de vertebrados e invertebrados, de los cuales, los siguientes se han asociado a humanos: Nosema (Nosema corneum, reclasificado como Vittaforma corneae; Nosema algerae, reclasificado inicialmente como Brachiola algerae y ahora como Anncaliia algerae), Pleistophora, Encephalitozoon, Enterocytozoon, Septata (reclasificado como Encephalitozoon), Trachipleistophora, Brachiola, Anncaliia, Tubulonosema, Endoreticulatus, y Microsporidium. Enterocytozoon bieneusi y Encephalitozoon intestinalis son las especies más comúnmente aisladas desde el aparato digestivo humano.

Morfología: Se caracterizan por la producción de esporas de resistencia que varían en tamaño dependiendo de la especie. Los asociados a infección humana miden de 1 a $4 \mu \mathrm{m}$, poseen un importante organelo de invasión: el tubo polar o filamento polar, el cual es enrollado al interior de la espora encerrando el núcleo, una vacuola posterior y una capa protectora (exospora) compuesta de proteínas y quitina que le confiere alta resistencia ambiental, permitiendo su dispersión en el agua y alimentos.

Patogenicidad: Fueron reconocidos como patógenos humanos en 1959, donde se asoció a una encefalitis en un niño y en 1985 aparecieron los primeros reportes de síndrome diarreico asociado en pacientes con infección por VIH/SIDA. También puede afectar a otros pacientes inmunocomprometidos, tal como receptores de trasplantes o sometidos a quimioterapia. La diarrea crónica es la forma clínica más frecuente, pudiéndose también presentarse en forma diseminada. La infección del tracto gastrointestinal en más de $90 \%$ es causada por E. bieneusi, y $10 \%$ restante por E. intestinalis.

Las especies de Microsporidia potencialmente patógenas para el hombre han sido identificadas en el agua y en animales. En Chile se describió un brote nosocomial de diarrea en niños inmunocomprometidos causada por la especie E. intestinalis. Dentro del estudio del brote se encontró presencia de este agente en el agua de los estanques y de la salida de los grifos.

Técnicas diagnósticas: Microscopia: El examen microscópico de frotis fecales, teñidos con Chromotrope 2R y sus variantes, son métodos económicos para el diagnóstico, aunque no permite la identificación de especie. La espora y su pared se tiñen de un rojo-rosado brillante (Figura 1), requiriendo un tiempo aproximado de 90 min. Existe otra tinción llamada "quick-hot Gram", que reduce el tiempo de procesamiento a menos de $10 \mathrm{~min}$ y proporciona una buena visualización de las esporas, las cuales se tiñen de violeta oscuro. Las tinciones quimiofluorescentes, como blanco de calcofluor, también son útiles en la identificación rápida de esporas en frotis fecales. Inmunofluorescencia directa: Existen anticuerpos monoclonales contra Encephalitozoon spp. y E. bieneusi que pueden ser de utilidad. RPC: La identificación molecular de las especies puede estandarizarse usando cebadores específicos de un género y análisis de secuenciación.

Tratamiento: En pacientes con infección por VIH/SIDA existe evidencia que la TARV permite controlar la infección. En pacientes con compromiso inmune e infección diseminada el tratamiento recomendado es albendazol $400 \mathrm{mg}$, dos veces al día, por 2-4 semanas. En queratoconjuntivitis se recomienda fumagilina tópica.

\section{Referencias bibliográficas}

1.- Han B, Weiss L M. Microsporidia: Obligate intracellular pathogens within the fungal kingdom. Microbiol Spectr 2017; 5: 1-17.

2.- Centers for Disease Control and Prevention. Microsporidiosis. https://www.cdc.gov/dpdx/microsporidiosis/index.html Fecha de acceso: 9 enero 2018.

3.- Capella-Gutiérrez S, Marcet-Houben M, Gabaldón T. Phylogenomics supports microsporidia as the earliest diverging clade of sequenced fungi. BMC Biology 2012; 10: 47.

4.- Coria P, Urízar C, Alba A, Noemí I, Pino A, Cerva J L. Agua potable como posible fuente de brote de diarrea por Microsporidium spp. en pacientes inmunocomprometidos en un hospital pediátrico. Rev Chilena Infectol 2016; 33: 373-9. 